\title{
Research on Influences of Lightning Current Amplitude and Wave-head Time to Overhead Line Lightning Overvoltage
}

\author{
Mochen Liu ${ }^{1}$, Ziyang $\mathrm{Li}^{2}$, Rui Jin ${ }^{1}$, Zhenyu Zou ${ }^{2}$, Chengbao Song ${ }^{1}$ and \\ Ranran Wang ${ }^{1, a, *}$
}

${ }^{1}$ College of Mechanical and Electronic Engineering, Shandong Agricultural University, Tai'an, Shandong, China

${ }^{2}$ Shandong electric power engineering consulting institute corp. Itd, Ji'nan, Shandong, China

awranran@163.com

Keywords: Lightning Over-voltage, Lightning Current Amplitude, Wave-head Time, Insulator Flash, ATP-EMTP

\begin{abstract}
Lightning over-voltage is the major cause of the transmission line interruption and the main reason that endangers the safety and reliability of transmission line system. This paper modelled a single loop overhead transmission line of $330 \mathrm{kV}$ with one ground wire based on ATP-EMTP to search the influences of lightning wave, amplitude and gradient to the overhead transmission when hit by back overrating voltage. Combining the feature of fast wave front over voltage and the analysis of model characteristic and the range of application, transmission line model, tower surge impedance model and tower ground resistance model were established, at the same time the insulator flash model was set up using the user defined module. Based on this model, this article chosen two parameters of lightning amplitude and wave-head time as variable to analyze the over voltage level of the $\mathrm{A} / \mathrm{B} / \mathrm{C}$ wires and terminal transformer. The results showed the influence of two parameters above and the critical condition of insulator flash, further more serving the designing of overhead transmission.
\end{abstract}

\section{Introduction}

Lightning disaster is an important factor affecting safe operation of transmission lines currently. Transmission line overvoltage caused by back flashover is one of the vital reasons of threatening safe operation of transmission lines and safety of electrical equipment. Therefore research on the character of overvoltage of back flashover has practical significance on the design of power system insulation. Lightning stroke can be divided into lightning shielding failure, which happens when lightning bypass the overhead ground wire and hit the lines directly, and back flashover, which occurs when overvoltage generated by lightning hitting overhead ground wire or tower arises on the lines. Overvoltage with very high amplitude on the lines and both ends of insulators can be led by lightning shielding failure and lightning flashover failure will be easily happened in the lines. However, the probability of lightning shielding failure is low because of the arrangements of overhead ground wires in the $35 \mathrm{KV}$ or above transmission system in China. Although the level of overvoltage in back flashover is relatively lower than in lightning shielding failure, the frequency of occurrence in back flashover is higher in the transmission line operation process, which means it is the main form of lightning disaster. Thus this paper focuses on the overvoltage in back flashover and includes researches of typical overhead lines overvoltage problems and rules of insulator arc over under the effect of two types and summing up to six lightning waves which have different lightning circuit amplitudes and lightning current wave-head time parameters. Then some gist to the parameters selection and confirmation of tower type, insulator number, tower ground resistor and so on in the design of overhead transmission lines can be provided, thereby the line lightning resisting level will be effectively improved.

Due to the difficulty of preparation in lightning overvoltage experiment conditions and observation of experiment phenomena, transmission lines always needed to be simulated, calculated and analysed to get its lightning resisting level in the process of transmission lines design. So both simulation and calculation of lightning overvoltage in transmission lines are inevitable. The software, ATP-EMTP, 
which has wide application, high simulation validity, enormous quantity of accurate mathematical models including lumped parameter elements, multiphase PI equivalent circuits, multiphase distributed parameter transmission lines, nonlinear time-varying elements and so on, which can always be used in system modelling, is commonly used in the field of electromagnetic simulation and commendably satisfy the simulation requirements of overvoltage problems. Hence this paper will employ it for simulation analysis in overvoltage problems in back flashover, specifically for the rules of influences which the changes of lightning circuit wave parameters have on the overvoltage.

\section{Modelling and simulation}

\subsection{Transmission lines and tower models}

When building models, the frequency range of research objects needed to be considered. It is important to consider transmission lines and tower model under the situation of fast wave-head overvoltage because this paper pays attention on the transmission lines overvoltage under the lightning waves. Lightning stroke point will generate lightning overvoltage when overhead transmission lines are struck by lightning, and this voltage will spread to both two directions along the lines. While traveling waves arriving at substation or other points, due to the changes of circuit parameters, refraction and reflection of waves will happen. Therefore in order to research overvoltage in back flashover, building transmission line and tower models with features of distributed parameters which are related to frequency is ineluctable.

Transmission line model

Bergeron model, which has complex lumped parameters, type $\Pi$ lumped parameter circuit model and J.Marti model based on frequency response are commonly used in overhead line models in power system.

1) Bergeron model: Basing on the lossless lines equivalent calculation which is realized by Bergeron characteristic line method, this model approximately considers influence of line losses by lumped resistor series in segmented form thus avoids direct solution of lines fluctuation equation concerning losses of resistors. When using it in transposed lines, it is called Clark model, otherwise it is called KClee model.

2) Type П lumped parameter circuit model: This model can be used in short line calculation and has enough accuracy for usual overhead transmission lines $(100-200 \mathrm{~km})$ in steady state calculation.

3) J.Marti model: This model is widely used and has parameters related to frequency. It can fairly well reflect the frequency response characters of transmission lines and fully meet the need of research in simulation of overvoltage in back flashover.

According to the requirements of simulation, four wires J.Marti model will be used to describe the over line single transmission line closing to the lightning stroke.

Tower model

Tower model is always ignored in the field of temporary overvoltage and slow-front voltage except tower foot ground resistor. But tower model is important when talking about the field of fast-front overvoltage because lightning waves propagation characteristics in tower have significant effects on lightning voltage calculation. Nowadays, scholars at home and abroad have established several tower models, which include lossless circuit model, loss and distortion less circuit model, subdivision model and four-stage model. Four-stage model can realize the attenuation of shock wave by using lumped resistors and satisfy fast attenuation character in high frequency field by using multiple of resistors and inductors. Reasonable selection of model parameters can realize the coincidence of arcing horn in every phase circuit and rules of measured waves. So this paper employs four-stage model to model tower electrical parameters.

\subsection{Insulator flashover and lightning current source model}

Insulator flashover model

Traditional insulator flashover model is usually confirmed by voltage-time curve under the $1.2 / 50 \mu \mathrm{s}$ standard lightning wave. However, lightning wave is not standard in the reality; there will be some 
differences in voltage-time characteristics of insulator thus experimental voltage-time curve can't reflect the actual process of physical breakdown. Hence leader propagation model is frequently used in flashover model. Leader propagation model is used for gist of insulator flashover and lightning overvoltage on the lines insulator is regarded as nonstandard wave. And voltage-time characteristic of insulator chain under the standard lightning wave is inapplicable for the insulating strength under the nonstandard lightning wave. The process of flashover of insulator chain in the impulse voltage can be deemed as the process of breakdown of air gap that has same length with insulator chain. When voltage of both ends of insulator chain exceeds critical coronal voltage, stream starts to exist. And leader will be generated if voltage overpasses the threshold value and flashover of insulator will happen when leader penetrates cross arm and conductors.

When time of withstanding voltage for insulator chain comes to and electric field intensity arrives at critical value, leader begins to develop with speed that changes with imposed voltage and length of rest gap. Once length of leader reaches length of gap, gap breaks down and insulator flashover appears. This method can accurately simulate the process of physical development in discharge and judge flashover of insulating gap under any kinds of waves.

lightning current source model

The amplitude of lightning current belongs to probability function; low amplitude lightning current (5-22kA) seldom hits transmission lines but hits overhead ground wire in a bigger probability. Lightning with high amplitude current hitting top of tower or overhead ground wire may cause back flashover of insulator chain.

The gradient and peak values of lightning current are important indexes influencing the level of lightning stroke overvoltage. According to the statistical analysis, the correlation coefficient of gradient and peak value in lightning current is $0.6 \sim 0.64$, which means they are closely correlated. The gradient of lightning current represents the speed of increase of lightning current along the time. Higher lightning current gradient means more damages to electrical equipment.

During the simulation in ATP-EMTP, lightning stroke model is expressed by equivalent model of multiple of current source and impedance that imitates real lightning channel wave impedance. Lightning current source model employs Heidler impulse source with parameters including amplitude, wave-head time, semi wave time and so on. The wave shape calculation of lightning current in Heidler's model is:

$$
\begin{aligned}
& i(t)=\frac{I_{0}}{\eta} \frac{\left[\frac{t}{\tau_{1}}\right]^{n}}{\left[\frac{t}{\tau_{1}}\right]^{n}+1} \cdot e^{\left[\frac{-t}{\tau_{2}}\right]} \\
& \eta=e^{\left[-\left[\frac{\tau_{1}}{\tau_{2}}\right]\left[\frac{\eta \tau_{2}}{\tau_{1}}\right]^{\frac{1}{n}}\right]}
\end{aligned}
$$

Where $I_{0}$ is peak value of lightning current, $\tau_{1}$ is wave-head time, $\tau_{2}$ is semi wave time, $n$ is constant of current gradient.

\subsection{Lightning back flashover overvoltage model building and simulation}

This paper builds $330 \mathrm{kV}$ single circuit model with single overhead ground wire and four lines overhead transmission lines. Three phase and overhead ground wire are erected over the 6 tower, tower span is $300 \mathrm{~m}$, terminals of lines are substations, and the whole model is showed in figure 1. Tower employs “上” glyph tower, and it's equivalent model of tower are depicted in figure 2. Stroke point is on the overhead ground wire located above the top of the 4th base tower, in figure 1 . 


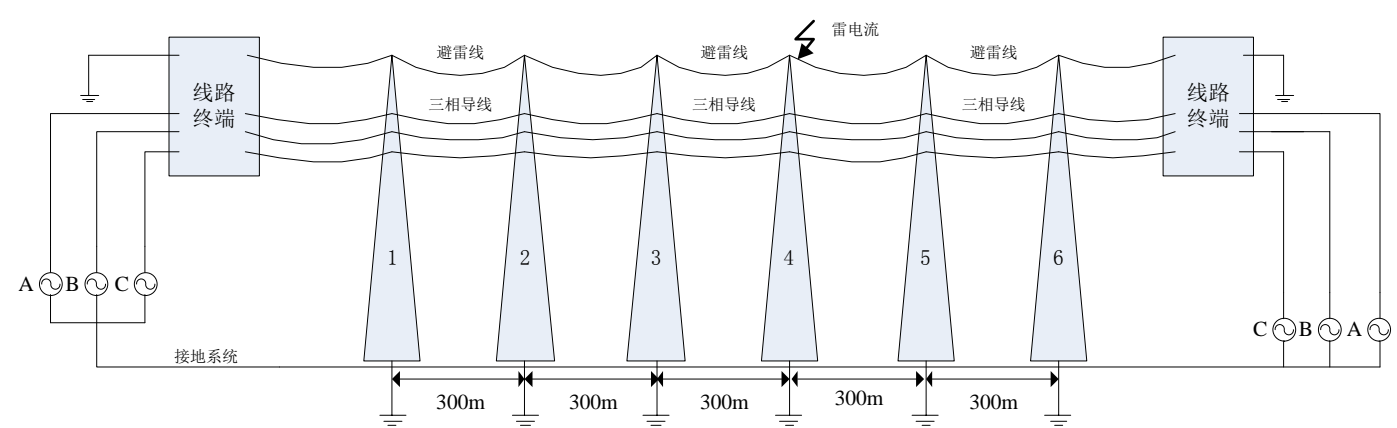

Figure 1. Overhead transmission lines schematic diagram

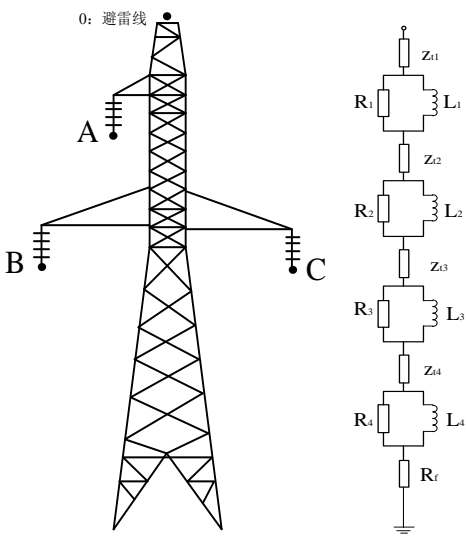

Figure 2. Tower construction and it's equivalent circuit

The influence of the changes in lightning current amplitude to the overvoltage in back flashover is simulated. Lightning wave is $4 / 50 \mu$ s typical lightning wave, which means the wave-head time is $4 \mu \mathrm{s}$, semi wave time is $50 \mu \mathrm{s}$, the range of amplitude is $84 \sim 120 \mathrm{kA}$, step is $2 \mathrm{kA}$. After several times of comparison and analysis of simulation results, three amplitude levels below are chose to proceed.

Lightning current amplitude is $84 \mathrm{kA}$ (no insulator flashover)

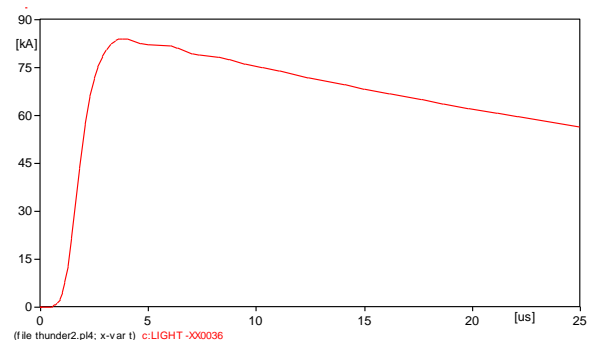

(a) Lightning current wave

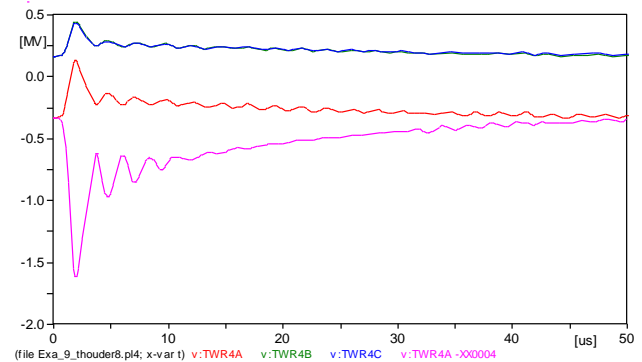

(c) Tower phase voltage wave and A phase insulator gap voltage

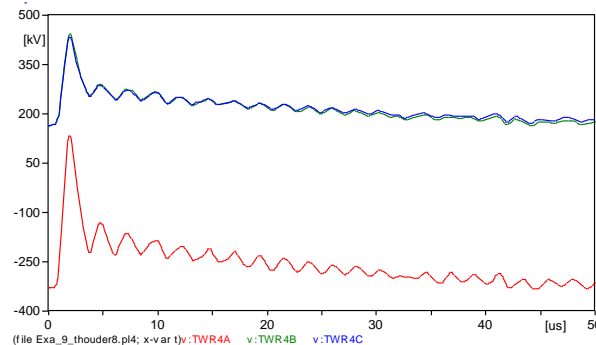

(b)Three phase voltage waves on stroke tower

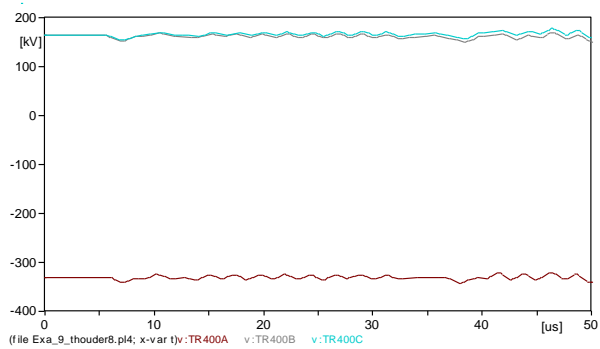

(d)Three phase voltage waves on transformer

Figure 3. The wave-head time of lightning current is $4 \mu \mathrm{s}$ and amplitude of lightning current is $84 \mathrm{kA}$

From the simulation results of Figure 3, when the wave-head time is $4 \mu \mathrm{s}$, amplitude is $84 \mathrm{kA}$, there is no insulator flashover. Insulator gap voltage is showed in Figure 3 (c), the highest value of three phase voltage of stroke tower is lower than $500 \mathrm{kV}$, and no much fluctuation of voltage happens, voltage tends to be stable after $50 \mu \mathrm{s}$. Voltage of transformer has less fluctuation during the semi wave 
time of lightning current, and then tends to be normal power frequency voltage. It's obvious that system is not affected too much when system is struck with no insulator flashover.

Lightning current amplitude is 90kA (insulator flashover critical point) and 120kA (lightning current amplitude maximum)
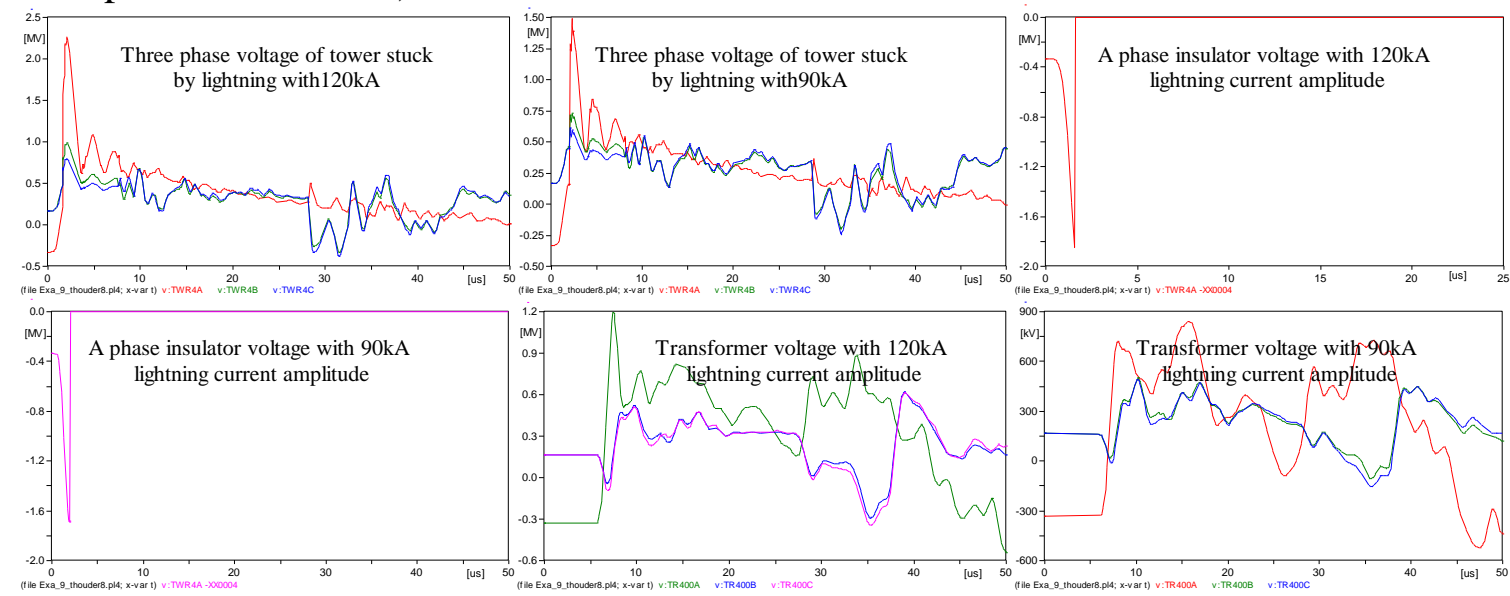

Figure 4. Wave-head time of lightning current is $4 \mu \mathrm{s}$, amplitude is $90 \mathrm{kA}$ and $120 \mathrm{kA}$.

From the simulation results of Figure 4, when wave-time of lightning current is $4 \mu$ s, amplitude is 90kA and 120kA, insulator flashover occurs. The voltages of insulator gap in breakdown are showed in Figure 4. The biggest amplitude value of three phase voltage in stroke tower increases with the arising level of lightning current amplitude, up to $2.3 \mathrm{MV}$, which is 8.5 times of lines, rated phase voltage peak value. The highest amplitude value of transformer phase voltage also ascends with arising level of lightning current amplitude, up to $1.2 \mathrm{MV}$, which is 4.5 times of rated transformer phase voltage peak value. After the analysis of simulation results above and data comparison, overvoltage in back flashover will cause huge damages to regular operation of transmission lines and system equipments safety under the circumstance of insulator flashover.

Select 2.5/50us typical lightning wave, which means that wave-head time is $2.5 \mu \mathrm{s}$, semi wave time is $50 \mu \mathrm{s}$, the range of amplitude is $70-84 \mathrm{kA}$, step is $2 \mathrm{kA}$. After several times of comparison and analysis of simulation results, lightning resisting level of lines decrease to $74 \mathrm{kA}$.

From the analysis of simulation result, when wave-head time becomes shorter, under the same level of lightning current amplitude, lightning resisting level of system decreases. When wave-head time is $4 \mu \mathrm{s}$, the critical current value of transmission lines insulator flashover is $90 \mathrm{kA}$, When wave-head time is $2.5 \mu \mathrm{s}$, this value is $74 \mathrm{kA}$, Decrease of wave-head time makes the flashover critical value reduced $17.8 \%$, which means gradient of lightning current will affect the lightning resisting level of lines.

\section{Conclusion}

This paper builds overhead transmission lines lightning stroke model by ATP-EMTP, simulates and analyses the influences that overvoltage level of system back flashover, lightning current amplitude and wave-head gradient have on the lightning resisting level. From the results of simulation analysis, when lightning current wave-head time/semi wave time is $4 \mu \mathrm{s} / 50 \mu \mathrm{s}$, insulator flashover critical current value is $90 \mathrm{kA}$, when it is $2.5 \mu \mathrm{s} / 50 \mu \mathrm{s}$, this value is $74 \mathrm{kA}$, the increase of wave-head gradient leads the $17.8 \%$ decrease of lines lighting resisting level. Analysis above illustrates that lightning current wave-head gradient has great effects on the system lightning resisting level and overvoltage. Bigger lightning current wave-head gradient means lower system lightning resisting level and bigger overvoltage level. Simultaneously, higher amplitude level of lightning current means higher overvoltage in back flashover when system is struck by lightning. 


\section{Acknowledgements}

This work is supported by Project of Shandong electric power engineering consulting institute corp. (37-K2016-060).

\section{References}

[1] Libin, Yang. (2009) Study on Lightning Protection Performance of Transmission Lines with Corona. Chongqing University.

[2] Pablo Torrez Caballero, Eduardo C. Marques Costa, Sérgio Kurokawa. (2016) Frequency -dependent line model in the time domain for simulation of fast and impulsive transients. International Journal of Electrical Power \& Energy Systems, Volume 80, 179-189

[3] Juan A. Martinez and Ferley Castro-Aranda. (2006). Influence of the Stroke Angle on the Flashover Rate of an Overhead Transmission Line. Power engineering Society General Meeting, IEEE.

[4] Juan A. Martinez-Velasco and Ferley Castro- Aranda. (2005). Modeling of Overhead Transmission Lines for Lightning Studies. International Conference on Power System Transients in Montreal, Canada.

[5] J.R. (1982) Marti, Accurate Modeling of Frenquency-dependent Transmission Lines in Electromagnetic Transient Simulations. IEEE Transactions on Power Apparatus and Systems. Vol. PAS-101

[6] Ya Azaki K, Olsen R G. (2004) Application of a corona onset criterion to calculation of corona onset voltage of stranded conductors. IEEE Tansactions on Dielectric and Electrical Insulation.

[7] YUAN Hai-yan, FU Zheng-cai, WEI Ben-gang, SUN Wei. (2009) Analysis of Lightning Shielding Failure Proof Level of UHV Transmission Lines Considering Corona Influences. Proceedings of the CSEE, 111-117

[8] Yamazaki K, Olsen R G. (2004) Application of a corona onset criterion to calculation of corona onset voltage of stranded conductors [J]. IEEE Trans. on Dielectrics and Electrical Insulation, 674-680. 